Tropical Journal of Pharmaceutical Research May 2019; 18 (5): 1009-1015

ISSN: $1596-5996$ (print); 1596-9827 (electronic)

(C) Pharmacotherapy Group, Faculty of Pharmacy, University of Benin, Benin City, 300001 Nigeria.

\title{
MiR-214 promotes renal fibrosis in diabetic nephropathy via targeting SOCS1
}

\author{
Weiwei $\mathrm{Xi}^{1}$, Xuming Zhao ${ }^{1}$, Meijun $\mathrm{Wu}^{2}$, Xueqin $\mathrm{Fu}^{1}$, Wenjuan $\mathrm{Jia}^{1}$, Mingxi $\mathrm{Lu}^{1}$, \\ Hua $\mathbf{L i}^{1 *}$ \\ ${ }^{1}$ Nephrology Department of Sir Run Run Shaw Hospital, ${ }^{2}$ Comprehensive Healthcare Department of the First Hospital of \\ Hangzhou, Zhejiang 310016, China
}

*For correspondence: Email: h_li@zju.edu.cn; Tel: +86-0571-86006875; Fax: +86-0571-86044817

Sent for review: 14 December 2018

Revised accepted: 25 April 2019

\begin{abstract}
Purpose: To elucidate how miR-214 regulates the pathogenesis of diabetic nephropathy (DN). Methods: The extent of fibrosis in DN mice kidneys was examined using Masson's staining. Quantitative polymerase chain reaction (qPCR) was used to determine the levels of miR-214. Dual luciferase reporter assay was used to identify the target of miR-214. The expression of fibrosis marker proteins of high glucose-stimulated NRK-52E cells transfected with miR-214 was determined using western blotting.

Results: Fibrosis in renal tissue of DN mice was significantly increased and miR-214 was upregulated $(p<0.001)$. Suppressor of cytokine signaling 1 protein (SOCS1) was the target gene of miR-214, and overexpression of miR-214 promoted fibrosis $(p<0.05, p<0.001)$. On the other hand, overexpression of SOCS1 inhibited this process, indicating that miR-214 promoted fibrosis via targeting SOCS1 ( $p<$ 0.001). Finally, inhibition of miR-214 c ameliorated renal fibrosis in DN mice $(p<0.01, p<0.001)$.

Conclusions: MiR-214 is upregulated in db/db DN mice kidney tissue; miR-214 regulates renal fibrosis in DN mice by targeting SOCS1.
\end{abstract}

Keywords: MiR-214, Renal fibrosis, Suppressor of cytokine signaling 1

\begin{abstract}
This is an Open Access article that uses a fund-ing model which does not charge readers or their institutions for access and distributed under the terms of the Creative Commons Attribution License (http://creativecommons.org/licenses/by/4.0) and the Budapest Open Access Initiative (http://www.budapestopenaccessinitiative.org/read), which permit unrestricted use, distribution, and reproduction in any medium, provided the original work is properly credited.

Tropical Journal of Pharmaceutical Research is indexed by Science Citation Index (SciSearch), Scopus, International Pharmaceutical Abstract, Chemical Abstracts, Embase, Index Copernicus, EBSCO, African Index Medicus, JournalSeek, Journal Citation Reports/Science Edition, Directory of Open Access Journals (DOAJ), African Journal Online, Bioline International, Open-J-Gate and Pharmacy Abstracts
\end{abstract}

\section{INTRODUCTION}

Diabetic nephropathy (DN), a common complication of diabetes, is considered to be a major cause of kidney failure [1,2]. With its increasing incidence, DN has become a global public health problem. In general, the unique pathological changes of DN, including mesangial cell (MC) proliferation, vascular mesangial expansion, and accumulation of abnormal extracellular matrix (ECM), leads to fibrosis of the glomerular sclerosis resistance index and ultimately to chronic renal failure [3]. These physiological changes dramatically decrease the quality of life, and even endanger the lives of patients [4].

MicroRNAs (miRNAs) are endogenously expressed and negatively regulated through targeting the 3'UTR regions of mRNAs [5]. miRNAs are essential for the pathogenesis of many human diseases, including cancer, 
diabetes, diabetic complications such as $\mathrm{DN}$, and other potential diseases [6-8]. Previous studies have reported that miR-214 is dramatically increased in the renal cortex of diabetic $\mathrm{db} / \mathrm{db}$ mice, and suppression of miR-214 reduces the levels of collagen IV, SM22, and $\alpha-S M A$, and partially recovers the levels of phosphatase and tensin homolog (PTEN) protein[9].

Cross-expression of PTEN and miR-214 protein under diabetic conditions suggests that miR-214 may be a new therapeutic target for DN [10]. Another study reported that miR-214 was increased in a kidney injury model, and genetic loss of miR-214 weakened interstitial fibrosis [9]. MiR-214 could facilitate fibrosis via the independent TGF- $\beta$ signaling pathway in renal injury, but the molecular mechanism of this process is still unknown [11].

Suppressors of cytokine signaling (SOCS) proteins are important negative regulators that control the size and duration of the JAK/STAT signaling via inhibiting kinase activity, binding to STAT, and affecting the proteasome degradation pathway[12]. Members of the SOCS family include a C-terminal SOCS cassette, which is involved in the proteasome, a variable $\mathrm{N}$-terminal domain, and a central SH2 domain [13].

This study showed that miR-214 was increased in kidney tissue of $\mathrm{db} / \mathrm{db}$ DN mice and high glucose (HG)-stimulated NRK-52E cells, which targeted the SOCS1 gene. Overexpression of miR-214 promoted HG-stimulated NRK-52E cell fibrosis, but SOCS1 could inhibit this progress. Together, these results showed that miR-214 promoted HG-stimulated NRK-52E cell fibrosis through targeting SOCS1.

\section{EXPERIMENTAL}

\section{$\mathrm{Db} / \mathrm{db}$ DN mouse model}

All animal experiments were conducted based on the "Guidelines for the Care and Use of Laboratory Animals" [14]. Six-8 weeks clean grade male $\mathrm{db} / \mathrm{db}$ mice with background strain C57BL/KsJ were purchased from the Beijing Huakang Biotechnology Co. (Beijing, China). During the experiments, the mice were kept under constant temperature conditions, and were free to eat standard feed and drinking water, with the light/dark alternated every $12 \mathrm{~h}$. The diabetic mice were then divided into two groups ( $\mathrm{n}=$ 10/each group) involving the, (1) $\mathrm{db} / \mathrm{db} \mathrm{DN}$ group $(\mathrm{db} / \mathrm{db})$ and (2) the $\mathrm{db} / \mathrm{db}$ DN group incubated with the miR-214 inhibitor (Invitrogen, Carlsbad, $\mathrm{CA}$, USA). Age-matched $\mathrm{db} / \mathrm{m}$ mice $(\mathrm{db} / \mathrm{m}, \mathrm{n}=$ $10)$ were used as controls. The kidney tissue was harvested and frozen at $-80^{\circ} \mathrm{C}$ for subsequent western blotting and quantitative polymerase chain reaction (qPCR).

\section{Cell culture}

NRK-52E cells were cultured in collagen-coated, polystyrene T-25 culture flasks with DMEM medium (Gibco, Eggenstein, Germany). The cells were incubated in a constant temperature incubator at $37^{\circ} \mathrm{C}$ with $5 \% \mathrm{CO}_{2}$. For the $\mathrm{HG}$ stimulated NRK-52E cell, the cells were cocultured with $30 \mathrm{mM}$ D-glucose for $24 \mathrm{~h}$ until they reached approximately $90 \%$ confluence.

\section{Western blotting}

Isolated kidney tissue and NRK-52E cells were harvested and the protein was extracted. The total proteins were collected by centrifugation. Equal amounts of proteins were resolved by SDS-PAGE and immunoblotted with primary rabbit anti-SOCS1, anti- $\alpha-S M A$, anti-TGF- $\beta 1$ (1:500; Cell Signaling Technology, Boston, MA, USA), anti-Smad3, anti-connective tissue growth factor (CTGF), and anti-fibronectin, or anticollagen I (1:200; Abcam, Cambridge, MA, USA). Goat anti-rabbit secondary antibody $(1: 3,000$; BioRad, Hercules, CA, USA) labeled with horseradish peroxidase was then incubated with the blots. Protein binding was determined using a storage phosphor screen, and the ratio of the target protein to the $\beta$-actin bands of the internal reference protein was used to define the quantification of protein expression. All experiments were performed in triplicate.

\section{Luciferase activity assay}

The gene of SOCS1-3'-UTR, which binds to miR214, was cloned into the psi-CHECK-2 Vector (Promega, Madison, WI, USA), and was designated as SOCS1 3'-UTR-WT. The SOCS1 3'-UTR-mutant (MUT) was obtained using a SiteDirected Mutagenesis Kit (Stratagene, San Diego, CA, USA). For the luciferase assay, miR214 mimics (Invitrogen) and normal control (NC)mimics were co-transfected with SOCS1 3'-UTRWT or SOCS1 3'-UTR-MUT into NRK-52E cells. The luciferase activity was measured after $24 \mathrm{~h}$ of transfection.

\section{Masson's stain}

$\mathrm{db} / \mathrm{db}$ DN mouse kidney tissue was harvested and stained according to the following protocol. The section samples were hydrated in phosphate-buffered saline for $5 \mathrm{~min}$ at $25^{\circ} \mathrm{C}$ and incubated in Bouin secondary fixative solution at $56{ }^{\circ} \mathrm{C}$ for $1 \mathrm{~h}$. The slides were washed with 
flowing $\mathrm{H}_{2} \mathrm{O}$ for $1-2$ min at room temperature to remove the yellow color, and the slides were cooled and briefly rinsed in deionized (DI) $\mathrm{H}_{2} \mathrm{O}$. Weigert's iron hematoxylin (hematoxylin $A$ and hematoxylin B) was used for staining for $5-10$ min at $25^{\circ} \mathrm{C}$. After washing with warm tap $\mathrm{H}_{2} \mathrm{O}$ for 10 min and rinsing with $\mathrm{DI}_{2} \mathrm{O}$, the cells were stained with Biebrich Scarlet-Acid Fuchsin for 5 15 min at $25^{\circ} \mathrm{C}$ to stain the cytoplasm.

After washing three times with $\mathrm{DI}_{2} \mathrm{O}$ for 1 min each wash, the mixture was placed in phosphomolybdic acid-phosphoric acid for 10 $15 \mathrm{~min}$ at room temperature to prepare the section for collagen staining. The slides were drained, and collagen was stained with Aniline Blue for $10 \mathrm{~min}$ and then washed twice with DI $\mathrm{H}_{2} \mathrm{O}$ for 1 min, each wash. After dehydration with $95 \%$ and $100 \%$ ethanol, 3-4 times per chamber, the samples were impregnated with xylene, 4-6 times per chamber, and then treated with resin medium. The tissue sections were then observed with an electron microscope and photographed.

\section{Expression of miR-214}

Total RNA from kidney tissue and NRK-52E cells was isolated and extracted using TRIzol reagent according to the manufacturer's instructions (Invitrogen) and quantitated using a NanoDrop2000 Spectrophotometer (Thermo Fisher Scientific, Waltham, MA, USA). One $\mu \mathrm{g}$ of RNA was used in the reverse transcription reaction using a MicroRNA Reverse Transcription Kit (Takara, Shiga, Japan). qPCR was performed using SYBR Premix (BioRad) using specific primers to amplify miR-214, U6 was used as a reference gene. The miR-214 primer sequences were as follows: forward, 5'CGGCGGACAGCAGGCACAGACA-3' and reverse, and GTTGGCTCTGGTGCAGGGTCCGAGGTATTC GCACCAGAGCCAACTCACGC-3'; and the U6 primer sequences were as follows: forward, 5'GTGCTCGCTTCGGCAGCACATATAC-3' and reverse, 5'-CCTTGCGCAGGGGCCATGCTAA3'.

\begin{tabular}{|l|l|l|}
\hline Gene & $\begin{array}{l}\text { Forward (5' - } \\
\text { 3') }\end{array}$ & Reverse (5' - 3') \\
\hline $\begin{array}{l}\text { miR- } \\
214\end{array}$ & $\begin{array}{l}\text { CGGCGGACA } \\
\text { GCAGGCACAG } \\
\text { ACA }\end{array}$ & $\begin{array}{l}\text { GTTGGCTCTGGTG } \\
\text { CAGGGTCCGAGG } \\
\text { TATTCGCACCAGA } \\
\text { GCCAACTCACGC }\end{array}$ \\
\hline U6 & $\begin{array}{l}\text { GTGCTCGCTT } \\
\text { CGGCAGCACA } \\
\text { TATAC }\end{array}$ & $\begin{array}{l}\text { CCTTGCGCAGGG } \\
\text { GCCATGCTAA }\end{array}$ \\
\hline
\end{tabular}

\section{Statistical analysis}

All the data are presented as mean \pm SEM. All experiments were independently performed at least three times. Values of $p<0.05, p<0.01$, or $p<0.001$ were regarded as statistically significant.

\section{RESULTS}

MiR-214 is upregulated in $\mathrm{db} / \mathrm{db}$ DN mouse kidney tissue and HG-stimulated NRK-52E cells

To detect the relationship between expression levels of miR-214 with DN, we constructed DN mice. First, we measured the extent of kidney fibrosis in DN mice by Masson's staining. The results showed that the degree of fibrosis of kidney tissue in DN mice was significantly higher than that of control mice (Figure $1 \mathrm{~A}$ ). We then detected the expression of miR-214 in kidney tissue of $\mathrm{db} / \mathrm{db} \mathrm{DN}$ mice using qPCR. The results showed that the level of miR-214 was upregulated in DN mice compared to control mice (Figure $1 \mathrm{~B}$ ), indicating that $\mathrm{DN}$ induced high expression of miR-214. To confirm this result, we constructed HG-stimulated NRK-52E cells and detected the expression level of miR214 in these cells. The QPCR results indicated that miR-214 was also upregulated in HGstimulated NRK-52E cells (Figure $1 \mathrm{C}$ ).

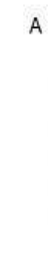

B

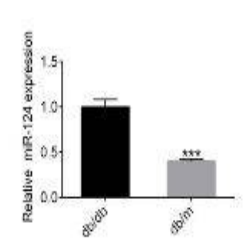

$d b / d b$

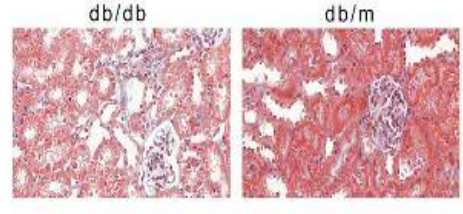

c

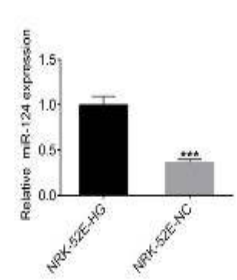

Figure 1: MiR-214 is upregulated in kidney tissue of $\mathrm{db} / \mathrm{db}$ diabetic nephropathy mice and high glucosestimulated NRK-52E cells. (A) Masson's staining was conducted to evaluate the level of renal fibrosis (left panel), and the extent of fibrosis. Student's $t$-test: ${ }^{* * *} p<$ 0.001 (right panel). (B and C) The reverse transcription-quantitative polymerase chain reaction detected the levels of miR-214 mRNA in $\mathrm{db} / \mathrm{db}$ and $\mathrm{db} / \mathrm{m}$ mice (B), or in high glucose-stimulated NRK-52E cells (C). Student's $t$-test: $\quad p<0.001$ 


\section{Target gene of miR-214 is SOCS1}

According to nucleotide sequence alignment, we found that miR-214 paired with the 3'-UTR of the SOCS1 gene (Figure $2 \mathrm{~A}$ ). To verify whether SOCS1 was the miR-214 target gene, we transfected NRK-52E cells with the normal control (NC)-mimic or miR-214-mimic, then cotransfected with SOCS1 wild-type (WT) or mutant (MUT) 3'-UTR, which were fused with a luciferase reporter. The results showed that compared with cells transfected with NC-mimic, transfection with the miR-214-mimic reduced the luciferase reporter gene expression with SOCS1 3'-UTR-WT, but not with SOCS1 3'-UTR-MUT (Figure $2 \mathrm{~B}$ ). Together, these results showed that SOCS1 was the target gene of miR-214.

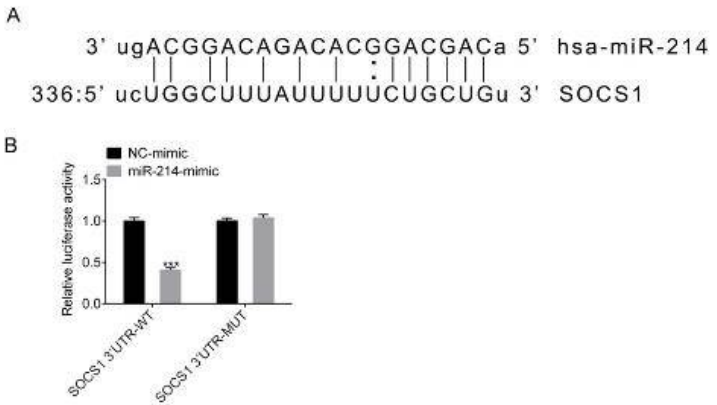

Figure 2: MiR-214 targets SOCS1 for downregulation. (A) Sequence alignment between miR-214 with the 3'UTR of the SOCS1 gene. (B) The dual luciferase reporter assay determined the relative fluorescence activity in NRK-52E cells transfected with the normal control (NC)-mimic + SOCS1 3'-UTR-wild-type (WT), miR-214-mimic + SOCS1 3'-UTR-WT, NC-mimic + SOCS1 3'-UTR-mutant (MUT), and miR-214-mimic + SOCS1 3'-UTR-MUT. Student's $t$-test, "* $p<0.001$

\section{MiR-214 promoted fibrosis of HG-stimulated NRK-52E cells}

To determinate the effect of miR-214 on NRK$52 \mathrm{E}$ cell fibrosis, we transfected the NC-mimic, miR-214-mimic, NC-inhibitor, or miR-214inhibitor into NRK-52E cells cultured in HG, then detected the transfection efficiency by qPCR. The results showed that NRK-52E cells transfected with the miR-214-mimic had higher accumulation of miR-214, and cells transfected with miR-214-inhibitor had decreased miR-214 accumulation (Figure $3 \mathrm{~A}$ ).

To further evaluate the effect of miR-214 on cell fibrosis, we determined the expression levels of the fibrosis marker genes, including SOCS1, $\alpha$ $S M A, T G F-\beta 1, t-S m a d 3$, CTGF, fibronectin, and collagen I by western blotting. The results showed that in cells transfected with the miR214-mimic, the expression of the SOCS1 gene was decreased, but the expressions of fibrosis marker genes were significantly increased (Fig. $3 B$ ), indicating that the fibrosis of NRK-52E cells was induced. In contrast, the expression of the SOCS1 gene was upregulated in cells transfected with the miR-214-inhibitor, and the expression levels of fibrosis markers were downregulated (Figure $3 \mathrm{~B}$ ). Together, these results indicated that miR-214 promoted HGstimulated NRK-52E cell fibrosis.

A
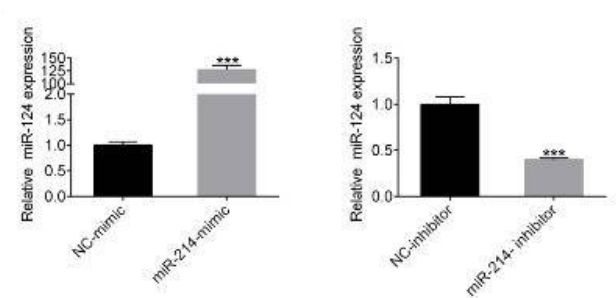

B
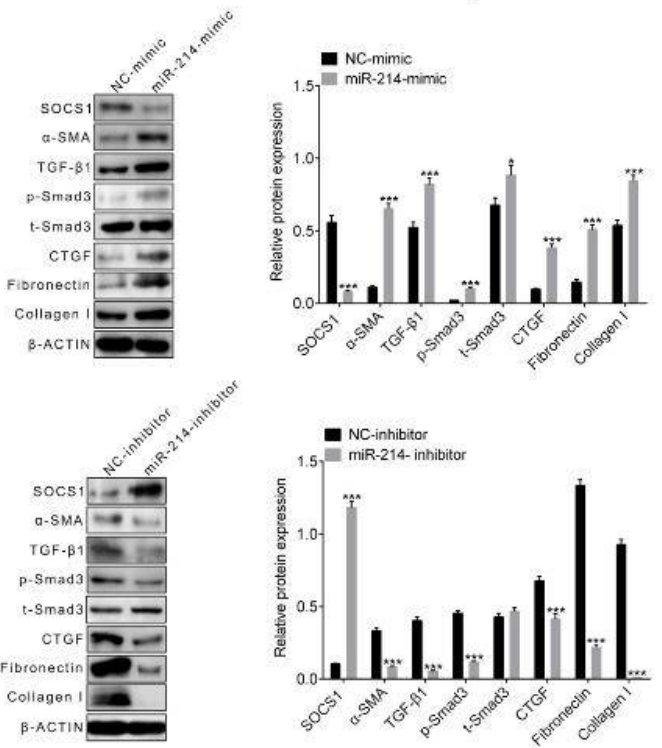

Figure 3: miR-214 promoted fibrosis of high glucosestimulated NRK-52E cells. (A) Reverse transcriptionquantitative polymerase chain reaction was used to detect the level of miR-214 mRNA in NRK-52E cells transfected with the normal control (NC)-mimic or miR214-mimic (left panel), or NC-inhibitor or miR-214inhibitor (right panel). (B) Western blotting evaluated the expression levels of SOCS1 and fibrosis marker proteins, including $\alpha$-SMA, TGF- $\beta 1$, t-Smad3, CTGF, fibronectin, and collagen $I$ in NRK-52E cells transfected with the NC-mimic or miR-214-mimic (upper panel), and NC-inhibitor or miR-214-inhibitor (bottom panel). $\beta$-actin accumulation was used as an internal reference control. Relative protein expression was quantified by Image $\mathrm{J}$ software (right panel). Student's $t$-test; ${ }^{*} p<0.05, \quad p<0.001$

\section{MiR-214 promoted HG-stimulated NRK-52E cell fibrosis by inhibiting SOCS1}

SOCS1 is a target gene of miR-214 (Figure 2); therefore, to verify whether miR-214 promoted fibrosis of HG-stimulated NRK-52E cells by 
inhibiting the SOCS1 gene, we transfected the NC-mimic, miR-214-mimic, miR-214-mimic, or SOCS1 into HG-stimulated NRK-52E cells. We then detected the expression levels of fibrosis marker proteins by western blotting. The results showed that the level of SOCS1 was downregulated in the miR-214-mimic, but was returned to normal levels in the miR-214-mimic and SOCS1 co-transfected cells. At the same time, the reduced expression levels of fibrosis markers in miR-214-mimic cells were partially restored to normal levels in the miR-214-mimic and SOCS1 co-transfected cells (Figure 4). Together, these results indicated that the fibrosis of NRK-52E cells, which was promoted by miR214 , was inhibited by SOCS1.
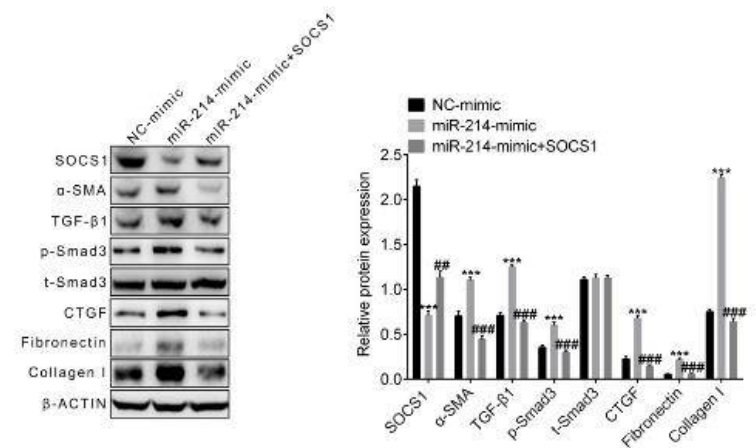

Figure 4: MiR-214 promoted high-glucose cultured NRK-52E cell fibrosis by inhibiting SOCS1. Western blotting detected the expression levels of SOCS1 and fibrosis marker proteins, including $\alpha-S M A$, TGF- $\beta 1$, tSmad3, CTGF, fibronectin, and collagen I in NRK-52E cells transfected with the normal control-mimic, miR214-mimic, or miR-214-mimic + SOCS1 (left panel). $\beta$ actin was used as a internal reference control. The relative protein expression was quantified by Image $\mathrm{J}$ software (right panel); ${ }^{\# \#}$ or ${ }^{* * \star}$ represent Student's $t$ test; $p<0.001$

\section{MiR-214 inhibitor improved renal fibrosis in DN mice}

To verify whether inhibition of miR-214 expression improved renal fibrosis in DN mice, we transfected NC-antagomir or miR-214antagomir into NRK-52E cells, then detected the expression of miR-214 by qPCR to evaluate the transfection efficiency. The results showed that the expression of miR-214 was downregulated in cells transfected with the miR-214-antagomir (Fig. 5A).

To further detect the degree of fibrosis of transfected cells, we determined the expression levels of fibrosis markers by western blotting. The results showed that the levels of SOCS1 were significantly increased in miR-214antagomir transfected cells, while the expressions of fibrosis markers were correspondingly decreased (Fig. 5B). Furthermore, we detected the degree of renal fibrosis in DN mice by Masson's staining and by the renal interstitial injury score. The results showed that compared with the control mice, the degree of fibrosis of kidney tissues transfected with the miR-214-antagomir was significantly decreased, and the degree of renal interstitial injury was also reduced (Fig. 5C). Together, these results indicated that the miR-214 inhibitor improved renal fibrosis in DN mice.

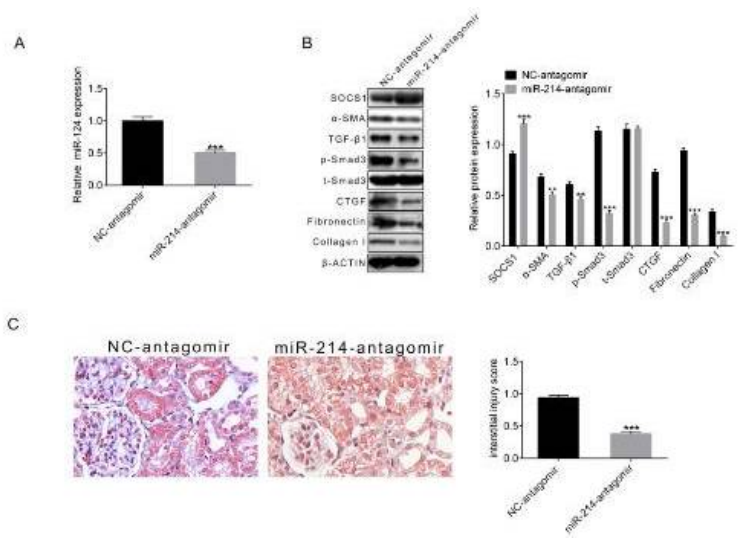

Figure 5: MiR-214 inhibitor improved renal fibrosis in diabetic nephropathy mice. (A) Reverse transcriptionquantitative polymerase chain reaction detected the levels of miR-214 mRNA in NRK-52E cells transfected with the NC-antagomir and miR-214-antagomir. (B) Western blotting detected the expression levels of SOCS1 and fibrosis marker proteins in NRK-52E cells transfected with the NC-antagomir and miR-214antagomir. $\beta$-actin was used as a control (left panel). The relative protein expression was quantified by Image J software (right panel). Student's t-test; ${ }^{* *} p<$ $0.01, \quad p<0.001$. (C) Masson's staining was conducted to detect the extend of renal fibrosis in NRK-52E cells transfected with the NC-antagomir and miR-214-antagomir (left panel), and the renal interstitial injury score was used to evaluate the extent of kidney fibrosis (right panel).

\section{DISCUSSION}

This study showed that expression of miR-214 was significantly upregulated in DN mice and HG-stimulated NRK-52E cells after targeting the SCOS1 gene. Our results indicated that while the expression of miR-214 was induced, the SCOS1 target gene was downregulated, ultimately leading to the upregulations of various fibrosis marker proteins and increasing renal fibrosis.

This study showed that miR-214 was significantly upregulated in DN mice, and downregulated by the SOCS1 target gene. Many studies have reported that proteins of the SOCS family negatively regulate a variety of cytokinemediated signaling pathways, which affect basic biological behaviors, including cell growth,

Trop J Pharm Res, May 2019; 18(5): 1013 
proliferation, and apoptosis[15]. Recent studies have also reported that the mRNA and protein levels of the SOCS1/3 are significantly upregulated in the glomeruli during the early stages of diabetes, accompanied by enhanced phosphorylation of JAK2 and STAT1, indicating that SOCS $1 / 3$ may negatively regulate the JAK/STAT signaling pathway in DN[16]. In the present study, miR-214 downregulated the expression of SOCS1, which indicated that miR214 may attenuate the negative regulation of SOCS1 protein on the JAK/STAT signaling pathway during $\mathrm{DN}$.

$\mathrm{DN}$ is a major diabetic microvascular complication that leads to renal failure. The main characteristic pathological changes of DN are abnormal proliferation of MCs, excessive accumulation of the ECM, and significant thickening of the basement membrane $[17,18]$. Previous studies have reported that during diabetes, miRNA plays a crucial role in regulating extracellular matrix ECM synthesis and gene expression during $M C$ hypertrophy [10]. It has been reported that miR-214 promotes the growth of diabetic MCs in vitro by targeting PTEN [11]. The results of the present study showed that inhibition of miR-214 reduced the expression levels of SM22, $\alpha-S M A$, and type IV collagen, but restored the expression of PTEN, and decreased albuminuria and mesangial expansion [19]. PTEN overexpression improved miR-214mediated MC hypertrophy, while the knockdown of PTEN mimicked MC hypertrophy. These results suggested that targeting miR-214 may be an effective strategy to alleviate diabetic kidney damage [20].

Glomeruli secrete diverse cytokines in a HGstimulated environment, including in the presence of TGF- $\beta 1$, causing increased accumulation of collagen, fibronectin, and laminin [21]. The extent of TIF is therefore reflected in the expression of collagens[22]. In the present study, the expression of collagen I was upregulated in cells transfected with the miR214-mimic, indicating an increase in the degree of fibrosis in renal tissue. Previous studies reported that TGF- $\beta 1$ is a determining factor in the pathogenesis of renal fibrosis, because it is significantly upregulated in many diseased kidney tissues with severe fibrosis, and activates the downstream Smad signaling pathway[23]. S. In the present study, under HG stimulation, the expression of miR-214 was increased, accompanied by the upregulation of fibrosis marker proteins including TGF- $\beta 1, p-S m a d 3, t-$ Smad3, and CTGF, indicating that miR-214 functions through the TGF- $\beta 1 / \mathrm{Smad} 3$ pathway to regulate renal fibrosis.
In addition, abnormal expression of miR-214 has been found in many human tumors, including colorectal cancer, nasopharyngeal carcinoma, gastric cancer, ovarian cancer, and breast cancer, which contributes insight into the pathogenesis and metastasis of these tumors [20]. Previous studies have reported that miR214 induces cell survival and platinum compound resistance by targeting PTEN and activation of the Akt pathway [24]. MiR-214 regulates the proliferation, migration, and invasion of gastric cancer cells by targeting the PTEN gene [25]. In the present study, miR-214 was upregulated in DN mice; however, whether miR-214 has other target genes besides SOCS1 in the regulation of renal fibrosis in mice will require further study.

\section{CONCLUSION}

MiR-214 targeted the SOCS1 gene, which inhibited the cytokine signaling pathways. The SOCS protein is a key physiological regulator of innate and adaptive immunity. MiR-214 RNA targets the SOCS1 gene, to improve the degree of renal tissue fibrosis caused by DN. Overall, the results of this study provide a possible strategy for the treatment of DN.

\section{DECLARATIONS}

\section{Conflict of interest}

No conflict of interest is associated with this work.

\section{Contribution of authors}

We declare that this work was done by the researchers listed in this article. All liabilities related with the content of this article will be borne by the authors. Weiwei $\mathrm{Xi}$ and $\mathrm{Hua} \mathrm{Li}$ designed all the experiments and revised the paper. Xuming Zhao,Wumei Jun and Xueqin Fu formed the experiments, Wenjuan Jia and Minxi Lu wrote the paper.

\section{Open Access}

This is an Open Access article that uses a funding model which does not charge readers or their institutions for access and distributed under the terms of the Creative Commons Attribution License (http://creativecommons.org/licenses/by/ 4.0) and the Budapest Open Access Initiative (http://www.budapestopenaccessinitiative.org/rea d), which permit unrestricted use, distribution, and reproduction in any medium, provided the original work is properly credited. 


\section{REFERENCES}

1. Wu L, Wang Q, Guo F, Ma X, Ji H, Liu F, Zhao Y, Qin G. MicroRNA-27a Induces Mesangial Cell Injury by Targeting of PPARgamma, and its In Vivo Knockdown Prevents Progression of Diabetic Nephropathy. Sci Rep. 2016; 6: 26072.

2. Qin L, Xifa S, Dawei X, Yangjing X, Kangting J, Jian X, Suqin Z. Role of hypoxia-inducible factor in diabetic myocardial hypertrophy. Trop J Pharm Res. 2016; 15(11): 2421-2427.

3. Brosius FC, Khoury CC, Buller CL, Chen $S$. Abnormalities in signaling pathways in diabetic nephropathy. Expert Rev Endocrinol Metab. 2010; 5(1): 51-64.

4. Shields J, Maxwell AP. Managing diabetic nephropathy. Clin Med (Lond). 2010; 10(5): 500-504.

5. Bartel DP. MicroRNAs: genomics, biogenesis, mechanism, and function. Cell. 2004; 116(2): 281-297.

6. Esquela-Kerscher A, Slack FJ. Oncomirs - microRNAs with a role in cancer. Nat Rev Cancer. 2006; 6(4): 259269.

7. Lagos-Quintana M, Rauhut R, Lendeckel W, Tuschl T. Identification of novel genes coding for small expressed RNAs. Science. 2001; 294(5543): 853-858.

8. Xiao C, Rajewsky K. MicroRNA control in the immune system: basic principles. Cell. 2009; 136(1):26-36.

9. Denby L, Ramdas V, McBride MW, Wang J, Robinson $H$, McClure J, Crawford W, Lu R, Hillyard DZ, Khanin R et al. miR-21 and miR-214 are consistently modulated during renal injury in rodent models. Am J Pathol. 2011; 179(2): 661-672.

10. Wang $X$, Shen E, Wang $Y$, Li J, Cheng $D$, Chen $Y$, Gui D, Wang N. Cross talk between miR-214 and PTEN attenuates glomerular hypertrophy under diabetic conditions. Sci Rep. 2016; 6(31506.

11. Denby L, Ramdas V, Lu R, Conway BR, Grant JS, Dickinson B, Aurora AB, McClure JD, Kipgen D, Delles $C$ et al. MicroRNA-214 antagonism protects against renal fibrosis. J Am Soc Nephrol. 2014; 25(1): 65-80.

12. Yoshimura A, Naka T, Kubo M. SOCS proteins, cytokine signalling and immune regulation. Nat Rev Immunol. 2007; 7(6): 454-465.

13. Trengove MC, Ward AC. SOCS proteins in development and disease. Am J Clin Exp Immunol. 2013; 2(1): 1-29.
14. Wolfensohn S, Lloyd M: Handbook of laboratory animal management and welfare, 4th edn. Chichester, West Sussex, UK: Wiley-Blackwell; 2013.

15. Starr R, Willson TA, Viney EM, Murray LJ, Rayner JR, Jenkins BJ, Gonda TJ, Alexander WS, Metcalf D, Nicola $N A$ et al. A family of cytokine-inducible inhibitors of signalling. Nature. 1997; 387(6636): 917-921.

16. Amiri F, Shaw S, Wang X, Tang J, Waller JL, Eaton DC, Marrero MB. Angiotensin II activation of the JAK/STAT pathway in mesangial cells is altered by high glucose. Kidney Int. 2002; 61(5): 1605-1616.

17. Jain SK, Rains JL. Toll-like receptor-4 and vascular inflammation in diabetes: editorial. Cytokine. 2011; 55(3): 446-447.

18. Wang $S$, Meng $X M, N g Y Y$, Ma FY, Zhou S, Zhang $Y$, Yang $C$, Huang XR, Xiao J, Wang $Y Y$ et al. TGFbeta/Smad3 signalling regulates the transition of bone marrow-derived macrophages into myofibroblasts during tissue fibrosis. Oncotarget. 2016; 7(8): 8809-8822.

19. Liu L, Hu X, Cai GY, Lv Y, Zhuo L, Gao JJ, Cui SY, Feng $Z$, Fu B, Chen XM. High glucose-induced hypertrophy of mesangial cells is reversed by connexin43 overexpression via PTEN/Akt/mTOR signaling. Nephrol Dialys Transplantat. 2012; 27(1): 90-525.

20. Penna E, Orso F, Taverna D. miR-214 as a key hub that controls cancer networks: small player, multiple functions. J Invest Dermatol. 2015; 135(4): 960-969.

21. Chen S, Jim B, Ziyadeh FN. Diabetic nephropathy and transforming growth factor- $\beta$ : transforming our view of glomerulosclerosis and fibrosis build-up. Sem Nephrol. 2003; 23(6): 532-543.

22. Wang $B$, Komers $R$, Carew $R$, Winbanks $C E, X u B$, Herman-Edelstein $M$, Koh $P$, Thomas $M$, JandeleitDahm K, Gregorevic $P$ et al. Suppression of microRNA29 Expression by TGF- $\beta 1$ Promotes Collagen Expression and Renal Fibrosis. J Am Soc Nephrol 2012; 23(2): 252-265.

23. Böttinger EP. TGF- $\beta$ in Renal Injury and Disease. Sem Nephrol. 2007; 27(3): 309-320.

24. Yang $H$, Kong $W$, He L, Zhao JJ, O'Donnell JD, Wang J, Wenham RM, Coppola D, Kruk PA, Nicosia SV et al. MicroRNA expression profiling in human ovarian cancer: miR-214 induces cell survival and cisplatin resistance by targeting PTEN. Cancer Res. 2008; 68(2): 425-433.

25. Yang TS, Yang $X H$, Wang $X D$, Wang $Y L$, Zhou $B$, Song ZS. MiR-214 regulate gastric cancer cell proliferation, migration and invasion by targeting PTEN. Cancer Cell Int. 2013; 13(1): 68. 